\title{
Alveolar Recruitment Maneuvers Under General Anesthesia: A Systematic Review of the Literature
}

\author{
Benjamin L Hartland RN, Timothy J Newell RN, and Nicole Damico MSNA CRNA
}

\author{
Introduction \\ Description of Condition \\ Description of Interventions \\ Significance of Review \\ Objectives \\ Methods \\ Types of Studies \\ Types of Subjects \\ Search Methods for Identification of Studies \\ Data Collection and Analysis \\ Selection of Studies \\ Assessment of Risk of Bias in Included Studies \\ Sensitivity Analysis \\ Results \\ Results of Search \\ Included Studies \\ Risk of Bias of Included Studies \\ Primary Outcomes \\ Secondary Outcomes \\ Discussion \\ Summary of Main Results \\ Primary Outcome Measures \\ Secondary Outcome Measures \\ Major Clinical Themes \\ Overall Completeness and Applicability of Evidence \\ Quality of Evidence \\ Potential Bias in the Review Process \\ Conclusions \\ Implications for Practice \\ Implications for Research
}

BACKGROUND: The sigh is a normal homeostatic reflex that maintains lung compliance and decreases atelectasis. General anesthesia abolishes the sigh reflex with rapid onset of atelectasis in $\mathbf{1 0 0 \%}$ of patients. Studies show a strong correlation between atelectasis and postoperative pulmonary complications, raising health-care costs. Alveolar recruitment maneuvers recruit collapsed alveoli, increase gas exchange, and improve arterial oxygenation. There is no consensus in the literature about the benefits of alveolar recruitment maneuvers. A systematic review is necessary to delineate their usefulness. METHODS: The search strategy included utilizing PubMed, CINAHL, the Cochrane Library, the National Guideline Clearinghouse, and all subsequent research reference lists up to January 2014. Inclusion criteria involved studies that compared the use of an alveolar 
recruitment maneuver with a control group lacking an alveolar recruitment maneuver in adult surgical subjects not suffering from ARDS or undergoing cardiac or thoracic surgeries. RESULTS: Six randomized controlled trials of the 439 studies initially identified achieved a score of $\geq 3$ on the Jadad scale and were included in this review. Alveolar recruitment maneuvers consisted of a stepwise increase in tidal volume to a plateau pressure of $30 \mathrm{~cm} \mathrm{H}_{2} \mathrm{O}$, a stepwise increase in PEEP to $20 \mathrm{~cm} \mathrm{H}_{2} \mathrm{O}$, or sustained manual inflations of the anesthesia reservoir bag to a peak inspiratory pressure of $40 \mathrm{~cm} \mathrm{H}_{2} \mathrm{O}$. Subjects in the alveolar recruitment maneuver groups experienced a higher intraoperative $\mathrm{P}_{\mathrm{aO}}$, with improved lung compliance. Different alveolar recruitment maneuvers were equally effective. There was a significant advantage when alveolar recruitment maneuvers were followed by PEEP application. CONCLUSIONS: Alveolar recruitment maneuvers followed by PEEP should be instituted after induction of general anesthesia, routinely during maintenance, and in the presence of a falling $\mathrm{S}_{\mathrm{pO}}$ whenever feasible. They allow the anesthesia provider to reduce the $\mathrm{F}_{\mathrm{IO}_{2}}$ while maintaining a higher $\mathrm{S}_{\mathrm{pO}_{2}}$, limiting the masking of shunts. Utilization of alveolar recruitment maneuvers may reduce postoperative pulmonary complications and improve patient outcomes. Key words: sigh breaths; alveolar recruitment maneuvers; lung-protective ventilation. [Respir Care 2015;60(4):609-620. (C) 2015 Daedalus Enterprises]

\section{Introduction}

\section{Description of Condition}

In 1964 , Bendixen et $\mathrm{al}^{1}$ found that awake adults sigh an average of $9-10$ times/h. The sigh breath is a normal homeostatic reflex characterized by a complex interaction between vagally mediated input and peripheral chemoreceptors that results in an increase in inspiration. ${ }^{2}$ The sigh breath functions to maintain pulmonary compliance. ${ }^{3}$ In a group of spontaneously breathing subjects, pulmonary compliance decreased in the absence of periodic sighs and returned to baseline after only 2 sigh breaths. Sigh breaths also minimize the alveolar-arterial oxygen difference $\left(\mathrm{P}_{(\mathrm{A}-\mathrm{a}) \mathrm{O}_{2}}\right)$ and maintain venous admixture within normal range. ${ }^{4}$

Sigh breaths help to release new surfactant and distribute it evenly on the alveolar surface and the distal airways. ${ }^{5,6}$ The fusion pore is the area on the alveolar type II cell that acts as a mechanical barrier to prevent further surfactant release. Sigh breaths open this barrier and replenish the available supply of surfactant. ${ }^{6}$

If sigh breaths occur in everyday life to prevent atelectasis as a normal homeostatic reflex, what happens when

The authors are affiliated with the Department of Nurse Anesthesia, Virginia Commonwealth University, Richmond, Virginia.

Supplementary material related to this paper is available at http:// www.rcjournal.com.

The authors have disclosed no conflicts of interest.

Correspondence: Benjamin L Hartland RN-BSN. E-mail: hartlandbl@vcu.edu.

DOI: $10.4187 /$ respcare. 03488 patients receive neuromuscular blocking drugs, are intubated, and are exposed to high concentrations of oxygen with a fixed tidal volume $\left(\mathrm{V}_{\mathrm{T}}\right)$ on a ventilator? General endotracheal anesthesia causes compression and absorption atelectasis through 3 main mechanisms: dyskinesis, increased $\mathrm{F}_{\mathrm{IO}_{2}}$, and ablation of the sigh breath. Dyskinesis causes a restriction in the movement of a patient's dependent diaphragm, resulting in a decrease in lung compliance. ${ }^{7}$ It also decreases movement of the dependent portion of the lungs, thereby decreasing functional residual capacity. ${ }^{8}$ These factors contribute to compression atelectasis, which occurs when the pressure distending the alveolus is reduced..$^{9}$ In a study using computed tomography, atelectasis was noted to occur in $100 \%$ of subjects undergoing general anesthesia. ${ }^{10}$

Absorption atelectasis occurs when the flux of oxygen from alveolar gas into capillary blood exceeds waste gas returning to the alveoli (as oxygen diffuses faster than nitrogen). This frequently occurs during induction of anesthesia when the $\mathrm{F}_{\mathrm{IO}_{2}}$ is increased to $100 \%$. Since oxygenated gas leaves the alveoli for the blood faster than waste gas (mostly nitrogen) returns to the alveoli, the alveoli shrink and eventually collapse, increasing atelectasis. ${ }^{11}$

In 1964, Bendixen et $\mathrm{al}^{4}$ hypothesized that constant ventilation with adequate but static $\mathrm{V}_{\mathrm{T}}$ in anesthetized patients would result in progressive atelectasis and shunting when sigh breaths were absent. They found that, on average, $\mathrm{P}_{\mathrm{aO}_{2}}$ fell $22 \%$ and pulmonary compliance fell $15 \%$ in the absence of sigh breaths. After a few minutes of slow, deep, sustained breaths, $\mathrm{P}_{\mathrm{aO}}$ rose an average of $150 \mathrm{~mm} \mathrm{Hg}$, reducing the shunt created by static $\mathrm{V}_{\mathrm{T}}$. The law of Laplace explains the increase in $\mathrm{P}_{\mathrm{aO}_{2}}$ : pressure $=2 \mathrm{~T} / \mathrm{r}$, where $\mathrm{T}=$ surface tension, and $\mathrm{r}=$ radius. When the radius of an alveolus is decreased, the pressure required to re-inflate 
that alveolus increases. Alveolar recruitment maneuvers provide the elevated pressure necessary to re-inflate collapsed alveoli and may help to prevent impending collapse.

Induction and maintenance of anesthesia with muscle paralysis and a fixed $\mathrm{V}_{\mathrm{T}}$ eliminate a patient's ability to generate the sigh breath. Without this inherent ability to decrease atelectasis and improve gas exchange, the patient is vulnerable to the consequences of atelectasis.

\section{Description of Interventions}

Alveolar recruitment maneuvers are described as vital capacity breaths, double $\mathrm{V}_{\mathrm{T}}$ breaths, and sigh breaths. ${ }^{12}$ Sigh breaths are to awake, spontaneously breathing patients as alveolar recruitment maneuvers are to anesthetized, mechanically ventilated patients. They use sustained increases in airway pressure (breath-holds) to recruit collapsed alveoli and improve arterial oxygenation. ${ }^{13}$

The method for achieving an alveolar recruitment maneuver tends to fall into 2 groups. Some authors consider sustained inflation of the lungs for 5-30 s to a prescribed peak inspiratory pressure (PIP) as representative of alveolar recruitment maneuvers. ${ }^{14-18}$ Others describe incrementally increasing PEEP in a stepwise manner as an alveolar recruitment maneuver. ${ }^{19,20}$ Both methods include the use of PEEP following an alveolar recruitment maneuver to maintain its benefit. For the purpose of this review, studies utilizing both methods will be used to determine the most effective application of an alveolar recruitment maneuver.

\section{Significance of Review}

Atelectasis likely occurs in up to $100 \%$ of patients undergoing general anesthesia. ${ }^{10}$ The intraoperative effects of atelectasis include an increase in the $\mathrm{P}_{(\mathrm{A}-\mathrm{a}) \mathrm{O}_{2}}$, an increase in pulmonary shunting, and a decrease in $\mathrm{S}_{\mathrm{pO}_{2}} \cdot{ }^{4,15}$ Atelectasis may increase the risk of volutrauma as a constant volume is imparted to a dwindling alveolar volume. Postoperative pulmonary complications are defined as any respiratory condition that adversely influences the clinical course of patients after surgery. ${ }^{21}$ Studies show a strong correlation between atelectasis and postoperative pulmonary complications. Atelectasis appears to be one of the primary mechanisms underlying acute lung injury, is a major cause of postoperative hypoxemia, and is associated with a prolonged ICU and hospital stay. ${ }^{21}$ Atelectasis may also contribute to serious postoperative pulmonary complications such as respiratory failure and pneumonia. ${ }^{22}$ Following cardiac bypass surgery, atelectasis causes hypoxemia and pulmonary shunting. ${ }^{23}$ Postoperative pulmonary complications represent a substantial economic burden due to longer hospital stays and increased health-care costs. ${ }^{21}$ In 2010 , postoperative pulmonary complications were es- timated to add nearly 3.5 billion dollars to annual healthcare costs. ${ }^{24}$

Despite their proposed benefits, there is no general consensus in the literature regarding the appropriate methods, timing, evaluation, and benefits of alveolar recruitment maneuvers during general anesthesia. Study outcomes range from improving arterial oxygenation, to no effect, to decreases in cardiac output and blood pressure. ${ }^{19,25} \mathrm{~A}$ thorough and focused systematic review regarding alveolar recruitment maneuvers is necessary to delineate their usefulness in improving patient outcomes both during and after general anesthesia.

\section{Objectives}

The primary objectives of this systematic review were: (1) to identify existing evidence in the literature; (2) to determine the usefulness, appropriate method, surgical population, and timing of alveolar recruitment maneuvers in the intraoperative period; (3) to determine the role of PEEP in alveolar recruitment maneuvers; (4) to identify methods for evaluating the efficacy of alveolar recruitment maneuvers; and (5) to highlight areas of future research related to alveolar recruitment maneuvers.

\section{Methods}

\section{Types of Studies}

Studies published before January 2014 were reviewed and were not limited by language. Studies based on subjects with ARDS were excluded because these subjects often require the use of different ventilatory strategies that may limit or skew the effects of standard alveolar recruitment maneuvers. Studies involving cardiac and thoracic surgeries were excluded because of surgical factors impacting normal heart and lung physiology. Animal studies were excluded because of the questionable generalizability of findings. To limit the effects of bias and covariates, only systematic reviews, quantitative meta-analyses, and randomized controlled trials (RCTs) were included. Finally, studies were limited to the intraoperative period, with assessment continuing in the immediate postoperative period for subjects undergoing general endotracheal anesthesia (Fig. 1).

\section{Types of Subjects}

Only adult subjects age 16 y and older were represented in these studies because of potential differences stemming from neonatal and pediatric anatomies. Alveolar recruitment maneuvers included either a stepwise increase in PEEP or $\mathrm{V}_{\mathrm{T}}$ using a ventilator or manual inflation of a subject's lungs to a predetermined PIP using an anesthesia 


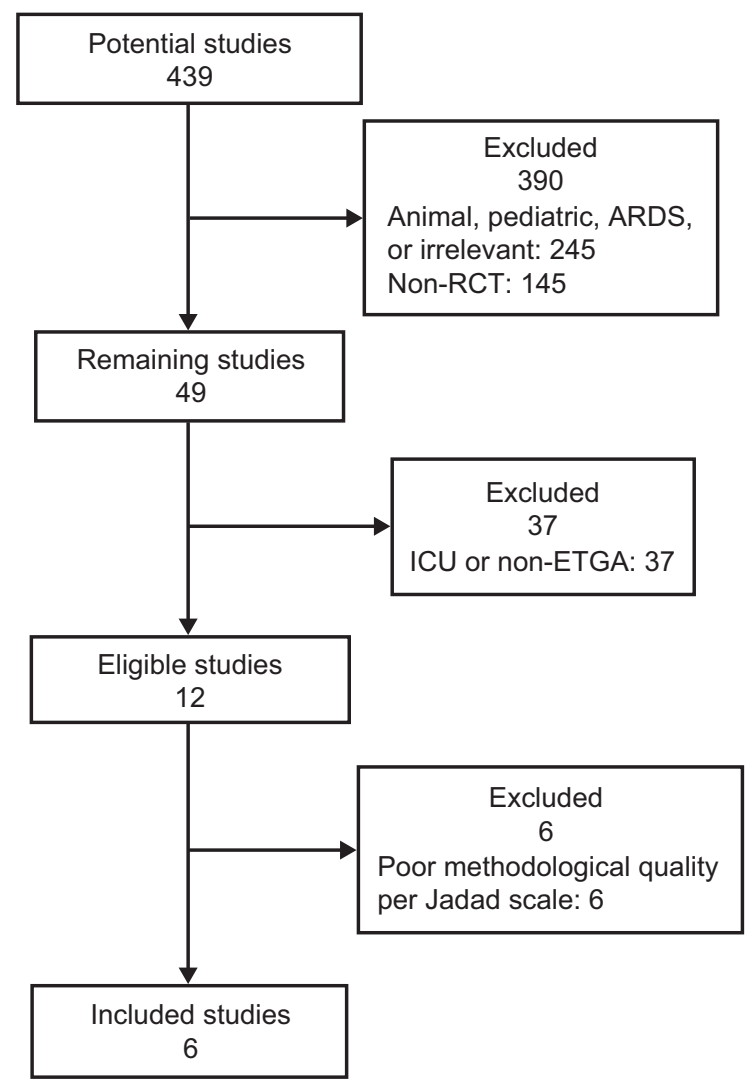

Fig. 1. Flow chart. $\mathrm{RCT}=$ randomized controlled trial. $\mathrm{ETGA}=$ endotracheal general anesthesia.

Table 1. Primary and Secondary Outcome Measures

\begin{tabular}{ll}
\hline \hline Primary Outcome Measures & \multicolumn{1}{c}{ Secondary Outcome Measures } \\
\hline Intraoperative $\mathrm{P}_{\mathrm{aO}_{2}}$ & Postoperative pulmonary complications \\
Pulmonary compliance & Postoperative $\mathrm{P}_{\mathrm{aO}_{2}}$ or $\mathrm{S}_{\mathrm{pO}_{2}}$ \\
$\mathrm{P}_{(\mathrm{A}-\mathrm{a}) \mathrm{O}_{2}}$ & Alveolar recruitment maneuver \\
& complications \\
$\mathrm{P}_{\mathrm{aO}_{2}} / \mathrm{F}_{\mathrm{IO}_{2}}$ & Alveolar recruitment maneuver frequency \\
& Airway resistance \\
& \\
\hline $\mathrm{P}_{(\mathrm{A}-\mathrm{a}) \mathrm{O}_{2}}=$ alveolar-arterial oxygen difference \\
\hline
\end{tabular}

reservoir bag. Each treatment group was compared with a control group that did not receive an alveolar recruitment maneuver. See Table 1 for a description of outcome measures.

\section{Search Methods for Identification of Studies}

The search included PubMed, CINAHL, the Cochrane Library, and the National Guideline Clearinghouse. Additional studies were detected by searching the reference lists of all included research reports. Search terms included: lung recruitment measures, alveolar recruitment mea- sures, perioperative recruitment maneuvers, PEEP, general anesthesia and chest $\mathrm{x}$-rays, preventing atelectasis during anesthesia/anesthesia, atelectasis and shunting during anesthesia/anesthesia, lung atelectasis and anesthesia/anesthesia, anesthesia/anesthesia and atelectasis development, sigh breaths, sigh breaths during ventilation, lung recruitment maneuvers, and perioperative atelectasis.

\section{Data Collection and Analysis}

\section{Selection of Studies}

Two reviewers (BLH and TJN) independently assessed all potential studies from the search strategy for inclusion. Consensus was reached through discussion or, if required, by consultation with a third reviewer (ND). The reviewers were not blinded to the authors or results of the studies. Data were independently extracted by the reviewers and cross-checked. Consensus was reached through discussion or, if required, by consultation with the third reviewer. A standard data extraction form was used (see the supplementary materials at http://www.rcjournal.com).

\section{Assessment of Risk of Bias in Included Studies}

The Jadad scale was used to evaluate methodological quality. ${ }^{26}$ The methodological quality assessment was performed by 2 reviewers as stated above. In cases of a discrepancy in the scores assigned by the primary reviewers, the third reviewer was used to reach a consensus. The Jadad scale includes 5 questions to evaluate the quality of RCTs. Each question is given a maximum score of 1 point. The questions include qualifiers that must be met to obtain a point: (1) Was the trial described as randomized? (The words random, randomly, or randomization must be used.) (2) Is the method of randomization appropriate? (The methods used to generate the sequence of randomization must be described.) (3) Was the study described as double-blind? (The words double-blind must be used.) (4) Is the method of blinding appropriate? (If not, 1 point is deducted.) (5) Is there a description of withdrawals and dropouts" (The reasons need to be included, and if there are no withdrawals, it must be stated as such.)

The scale awards $1-5$ points to RCTs. RCTs with $\leq 2$ points or less are considered low-quality studies, and RCTs with $\geq 3$ points are considered high-quality studies. ${ }^{26}$

\section{Sensitivity Analysis}

The following strategies were used for the sensitivity analysis: excluding unpublished RCTs, excluding RCTs 


\section{Alveolar Recruitment Maneuvers Under General Anesthesia}

Table 2. Inclusion and Exclusion Criteria in Studies Included in This Review

\begin{tabular}{|c|c|c|}
\hline Study & Inclusion Criteria & Exclusion Criteria \\
\hline Almarakbi et al ${ }^{27}$ & $\begin{array}{l}\text { ASA II, } 18-60 \text { y old, BMI }>30 \mathrm{~kg} / \mathrm{m}^{2} \\
\text { elective laparoscopic banding surgery }\end{array}$ & $\begin{array}{l}\text { Asthma, COPD, restrictive lung disease, increased intracranial pressure, } \\
\text { smoking history }\end{array}$ \\
\hline Pang et al ${ }^{14}$ & $\begin{array}{l}\text { ASA I-II, 16-70 y old, elective laparoscopic } \\
\text { cholecystectomy }\end{array}$ & $\begin{array}{l}\text { Pre-existing cardiac and respiratory disease requiring treatment, } \\
\text { spontaneous pneumothorax history, evidence of hemodynamic } \\
\text { insufficiency }\end{array}$ \\
\hline Severgnini et al ${ }^{28}$ & $\begin{array}{l}\text { Elective non-laparoscopic abdominal surgery } \\
\text { under general anesthesia expected to last } \\
>2 \mathrm{~h},>18 \text { y old }\end{array}$ & $\begin{array}{l}\text { BMI }>40 \mathrm{~kg} / \mathrm{m}^{2} \text {; laparoscopic or emergency surgery; previous lung } \\
\text { surgery; persistent hemodynamic instability; intractable shock } \\
\text { considered unsuitable for the study by the subject's managing } \\
\text { physician; COPD history; repeated systemic corticosteroid therapy } \\
\text { for exacerbations of COPD, asthma, or sleep disorders; recent } \\
\text { immunosuppressive medication defined as need for chemotherapy or } \\
\text { radiation therapy; < } 2 \text { months after chemotherapy or radiation } \\
\text { therapy; severe cardiac disease defined as New York Heart } \\
\text { Association class III or IV or acute coronary syndrome; persistent } \\
\text { ventricular tachyarrhythmias; pregnancy (by lab testing); acute lung } \\
\text { injury or ARDS, expected to require prolonged postoperative } \\
\text { mechanical ventilation; any neuromuscular disease; contraindications } \\
\text { to position an epidural catheter because of major clotting disorders } \\
\text { or sign of infection at the site of the procedure }\end{array}$ \\
\hline Sprung et al ${ }^{29}$ & $\mathrm{BMI}>40 \mathrm{~kg} / \mathrm{m}^{2}$, open bariatric surgery & $\begin{array}{l}\text { Abnormalities in spirometry }\left(\mathrm{FEV}_{1}<50 \% \text { of predicted, } \mathrm{FVC}<50 \%\right. \\
\text { of predicted), active asthma (requiring bronchodilator therapy), } \\
\text { previous lung surgery, home oxygen therapy }\end{array}$ \\
\hline Weingarten et al ${ }^{20}$ & $>65$ y old, major open abdominal surgery & $\begin{array}{l}\text { Significant pulmonary disease with abnormalities in spirometry } \\
\text { consistent with either obstructive or restrictive pulmonary disease, } \\
\text { active asthma (requiring chronic bronchodilator therapy), previous } \\
\text { lung surgery, home oxygen therapy, significant cardiac dysfunction } \\
\text { (left ventricular ejection fraction }<40 \% \text { ), BMI }>35 \mathrm{~kg} / \mathrm{m}^{2}\end{array}$ \\
\hline Whalen et al ${ }^{19}$ & $\begin{array}{l}\text { ASA II/II/III, } 25-65 \text { y old, BMI }>40 \mathrm{~kg} / \mathrm{m}^{2} \text {, } \\
\text { laparoscopic bariatric Roux-en-Y operations }\end{array}$ & $\begin{array}{l}\text { No significant preoperative pulmonary disease }\left(\mathrm{FEV}_{1}<50 \% \text { of }\right. \\
\text { predicted, FVC }<50 \% \text { of predicted), active asthma, home oxygen } \\
\text { therapy }\end{array}$ \\
\hline
\end{tabular}

ASA $=$ American Society of Anesthesiologists

$\mathrm{BMI}=$ body mass index

published as abstracts, and excluding RCTs of lower quality as assessed by the Jadad scale (score of $<3$ ).

\section{Results}

\section{Results of Search}

See Table 2 for inclusion and exclusion criteria and Table 3 for demographic variables. Of the 439 studies originally identified, 12 studies that met the inclusion criteria were retrieved for further scrutiny. Agreement between reviewers was achieved in all but 2 studies, which were subsequently sent to the third reviewer for further evaluation. Only one of these 2 studies was included, for a total of 6 studies receiving a Jadad score of $\geq 3 \cdot 14,19,20,27-29$ The 2013 study by Futier et $\mathrm{al}^{30}$ was not included because of the excessively large $\mathrm{V}_{\mathrm{T}}$ in the control group (10$12 \mathrm{~mL} / \mathrm{kg}$ ), as well as the lack of a protocol to account for confounding variables with their primary outcome measurements.

\section{Included Studies}

Interventions. The primary intervention in all 6 studies was the utilization of alveolar recruitment maneuvers. The method for performing an alveolar recruitment maneuver varied among studies. In addition, the amount of PEEP and $\mathrm{V}_{\mathrm{T}}$ differed between control and intervention groups among the studies (Table 4). For example, 3 studies compared subjects with higher $\mathrm{V}_{\mathrm{T}}$ and no PEEP with subjects with lower $\mathrm{V}_{\mathrm{T}}$, alveolar recruitment maneuvers, and PEEP. ${ }^{14,20,28}$ The frequency of the alveolar recruitment maneuvers also varied depending upon the study.

Subjects. Subjects in all studies underwent abdominal surgery. Three studies involved open procedures, ${ }^{20,28,29}$ and 3 studies involved laparoscopic surgery. ${ }^{14,19,27}$ The subjects in all 3 laparoscopic studies were rated as American Society of Anesthesiologists classification I-III. ${ }^{14,19,27}$ Subjects in 5 studies had an average body mass index of $>25 \mathrm{~kg} / \mathrm{m}^{2} .{ }^{19,20,27-29}$ Two studies included subjects with a 


\section{Alveolar Recruitment Maneuvers Under General Anesthesia}

Table 3. Demographic Variables in Studies Included in This Review

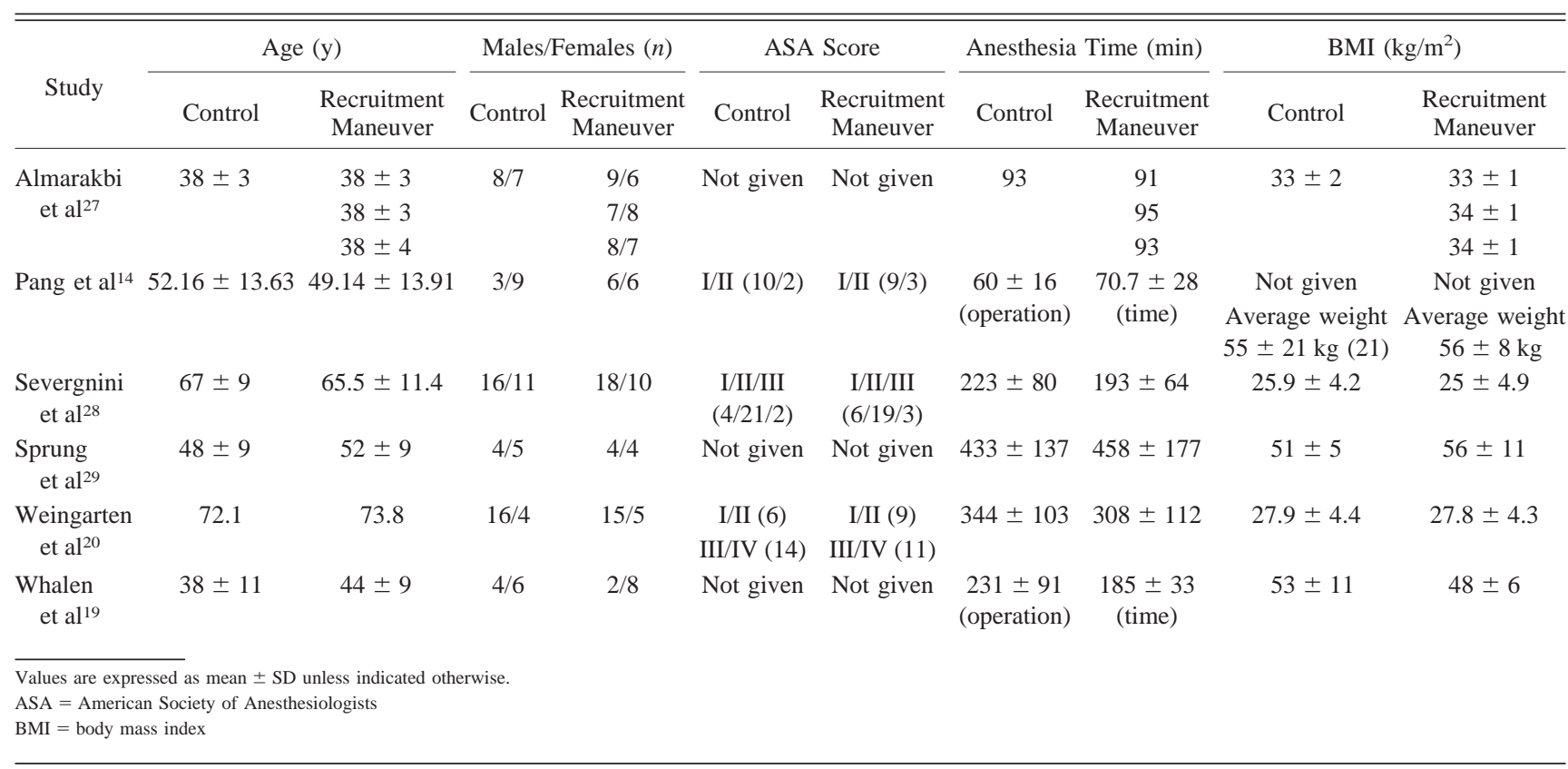

body mass index $>50 \mathrm{~kg} / \mathrm{m}^{2}{ }^{19,29}$ In 5 studies, the average age of subjects was $>40 \mathrm{y}$. Two studies included subjects with a mean age of $>65 \mathrm{y} \cdot{ }^{14,20,28,29}$ The ratio between men and women varied with each study, but overall, there was a slightly higher number of male subjects. Specific exclusion criteria are shown in Table 2. All studies excluded subjects with significant pre-existing lung disease.

Duration of Studies. Most studies finished the majority of their outcome measures in the immediate postoperative period. Although postoperative protocols were not delineated, 4 of the 6 studies included hospital stay as a secondary outcome measure. ${ }^{19,20,27,28}$ The time to hospital discharge varied from days to weeks.

\section{Risk of Bias of Included Studies}

All studies were RCTs that received a Jadad score of $\geq 3$. All of the study reports included a description of the randomization technique. Three of the studies included an assessment of blinding. ${ }^{19,27,28}$ Whalen et al ${ }^{19}$ also included blinding by the researcher collecting postoperative data. There were no dropouts in 4 studies..$^{14,19,20,27}$ In the other 2 studies, the researchers explained the reason for dropouts. Neither of these studies included an intention-to-treat analysis. ${ }^{28,29}$

\section{Primary Outcomes}

See Table 5 for primary and secondary outcomes of included studies.
Intraoperative $\mathbf{P}_{\mathrm{aO}_{2}}$. There was an increase in intraoperative $\mathrm{P}_{\mathrm{aO}}$ in the alveolar recruitment maneuver groups compared with control groups in the 4 studies in which this outcome was measured. ${ }^{14,19,20,27}$ Sprung et al ${ }^{29}$ included $\mathrm{P}_{\mathrm{aO}} / \mathrm{F}_{\mathrm{IO}_{2}}$ in their results, whereas Severgnini et al ${ }^{28}$ included only intraoperative $\mathrm{S}_{\mathrm{pO}_{2}}$.

Pulmonary Compliance. There was an increase in pulmonary compliance in the alveolar recruitment maneuver groups compared with the control groups in 4 of the 5 studies in which this outcome was measured. ${ }^{19,20,27,29} \mathrm{Sev}$ ergnini et $\mathrm{al}^{28}$ found no difference in pulmonary compliance among groups, whereas Pang et al ${ }^{14}$ did not include this outcome measure in their study.

$\mathbf{P}_{(\mathrm{A}-\mathrm{a}) \mathbf{O}_{2}}$. None of the studies included $\mathrm{P}_{(\mathrm{A}-\mathrm{a}) \mathrm{O}_{2}}$ measurements in their results.

$\mathbf{P}_{\mathrm{aO}_{2}} / \mathbf{F}_{\mathbf{I O}_{2}}$. There was an increase in $\mathrm{P}_{\mathrm{aO}_{2}} / \mathrm{F}_{\mathrm{IO}_{2}}$ in the alveolar recruitment maneuver groups compared with the control groups in the 3 studies that included this outcome measure. ${ }^{19,20,29}$

\section{Secondary Outcomes}

Postoperative Pulmonary Complications. Four studies found no difference in the occurrence of postoperative pulmonary complications. Almarakbi et $\mathrm{al}^{27}$ found that subjects in the alveolar recruitment maneuver group with PEEP had the shortest hospital stays. Severgnini et al ${ }^{28}$ reported a higher occurrence of postoperative pulmonary 


\section{Alveolar Recruitment Maneuvers Under General Anesthesia}

Table 4. Description of Intervention and Control Groups

\begin{tabular}{|c|c|c|}
\hline Study & Control Group & Intervention Group \\
\hline Almarakbi et al27 & $\mathrm{PEEP}=10 \mathrm{~cm} / \mathrm{H}_{2} \mathrm{O}(n=15)$ & $\begin{array}{l}\text { Experimental groups ( } n=15 \text { in each group): } \\
\text { (1) Single alveolar recruitment maneuver group without PEEP: PIP }=40 \mathrm{~cm} / \mathrm{H}_{2} \mathrm{O} \\
\text { held for } 15 \mathrm{~s} \\
\text { (2) Single alveolar recruitment maneuver group with PEEP: PIP }=40 \mathrm{~cm} / \mathrm{H}_{2} \mathrm{O} \\
\text { held for } 15 \mathrm{~s} \text {, then PEEP }=10 \mathrm{~cm} / \mathrm{H}_{2} \mathrm{O} \text { for rest of surgery } \\
\text { (3) Repeated alveolar recruitment maneuver group with PEEP: PIP }=40 \mathrm{~cm} / \mathrm{H}_{2} \mathrm{O} \\
\text { held for } 15 \mathrm{~s} \text {, then PEEP }=10 \mathrm{~cm} / \mathrm{H}_{2} \mathrm{O} \text {, repeated every } 10 \mathrm{~min}\end{array}$ \\
\hline Pang et al ${ }^{14}$ & $\mathrm{~V}_{\mathrm{T}}=10 \mathrm{~mL} / \mathrm{kg}, \mathrm{PEEP}=0(n=12)$ & $\begin{array}{l}\text { Following intubation, manual inflation to PIP }=40 \mathrm{~cm} / \mathrm{H}_{2} \mathrm{O} \text { without PEEP for } 10 \\
\text { breaths for } 1 \mathrm{~min} \text {, then placed back on ventilator with PEEP }=5 \mathrm{~cm} / \mathrm{H}_{2} \mathrm{O} \text { and } \\
\mathrm{V}_{\mathrm{T}}=10 \mathrm{~mL} / \mathrm{kg}(n=12)\end{array}$ \\
\hline Severgnini et al ${ }^{28}$ & $\begin{array}{l}\mathrm{V}_{\mathrm{T}}=9 \mathrm{~mL} / \mathrm{kg} \text { of IBW, PEEP }=0 \\
\quad(n=27)\end{array}$ & $\begin{array}{l}\mathrm{V}_{\mathrm{T}}=7 \mathrm{~mL} / \mathrm{kg} \text { of IBW, PEEP }=10 \mathrm{~cm} \mathrm{H}_{2} \mathrm{O} \text {, alveolar recruitment maneuver } \\
\text { performed after intubation, after any disconnect, and before extubation, provided } \\
\text { stable vital signs; alveolar recruitment maneuver defined as setting PIP at } \\
45 \mathrm{~cm} \mathrm{H}_{2} \mathrm{O}, \mathrm{I}: \mathrm{E}=3: 1 \text {, then } \mathrm{V}_{\mathrm{T}} \text { increased in steps of } 4 \mathrm{~mL} / \mathrm{kg} \text { of IBW until } \\
\text { plateau pressure }=30 \mathrm{~cm} \mathrm{H}_{2} \mathrm{O} \text {, then } 3 \text { breaths, then returned to baseline }(n=28)\end{array}$ \\
\hline Sprung et $\mathrm{al}^{29}$ & $\mathrm{~V}_{\mathrm{T}}=8 \mathrm{~mL} / \mathrm{kg}$, PEEP $=4(n=9)$ & $\begin{array}{l}\text { Stepwise increase in PEEP from } 4 \text { to } 10 \mathrm{~cm} \mathrm{H}_{2} \mathrm{O} \text { for } 3 \text { breaths, } 10 \text { to } 15 \mathrm{~cm} \mathrm{H}_{2} \mathrm{O} \text { for } \\
3 \text { breaths, } 15 \text { to } 20 \mathrm{~cm} \mathrm{H}_{2} \mathrm{O} \text { for } 10 \text { breaths, with maximum PIP }=50 \mathrm{~cm} \mathrm{H}_{2} \mathrm{O} \text {; } \\
\text { PEEP then set at } 12 \mathrm{~cm} \mathrm{H}_{2} \mathrm{O} \text {; alveolar recruitment maneuvers repeated } 30 \text { and } \\
60 \text { min after first recruitment (following intubation and placement of arterial line), } \\
\text { then hourly }(n=8)\end{array}$ \\
\hline Weingarten et al ${ }^{20}$ & $\begin{array}{l}\mathrm{V}_{\mathrm{T}}=10 \mathrm{~mL} / \mathrm{kg} \text { of IBW, PEEP }=0 \\
\quad\left(\text { intrinsic } \mathrm{PEEP}=2.5 \mathrm{~cm} \mathrm{H}_{2} \mathrm{O}\right) \\
(n=20)\end{array}$ & $\begin{array}{l}\mathrm{V}_{\mathrm{T}}=6 \mathrm{~mL} / \mathrm{kg} \text { of IBW, PEEP }=4 \mathrm{~cm} \mathrm{H}_{2} \mathrm{O} \text {, alveolar recruitment maneuver } \\
\text { performed after intubation (exact time not given), } 30 \text { and } 60 \text { min after the first } \\
\text { alveolar recruitment maneuver, hourly thereafter; alveolar recruitment maneuver } \\
\text { defined as incrementally increasing PEEP from } 4 \text { to } 10 \mathrm{~cm} \mathrm{H}_{2} \mathrm{O} \text { for } 3 \text { breaths, } \\
15 \mathrm{~cm} \mathrm{H}_{2} \mathrm{O} \text { for } 3 \text { breaths, then } 20 \mathrm{~cm} \mathrm{H}_{2} \mathrm{O} \text { PEEP for } 10 \text { breaths; after alveolar } \\
\text { recruitment maneuver, PEEP set to } 12 \mathrm{~cm} \mathrm{H}_{2} \mathrm{O} \text {, not stated if subsequent } \\
\text { recruitment maneuvers decreased to } 4 \mathrm{~cm} \mathrm{H}_{2} \mathrm{O} \text { to start }(n=20)\end{array}$ \\
\hline Whalen et al ${ }^{19}$ & $\begin{array}{l}\mathrm{V}_{\mathrm{T}}=8 \mathrm{~mL} / \mathrm{kg} \text { of IBW, PEEP }=4 \\
\quad(n=10)\end{array}$ & 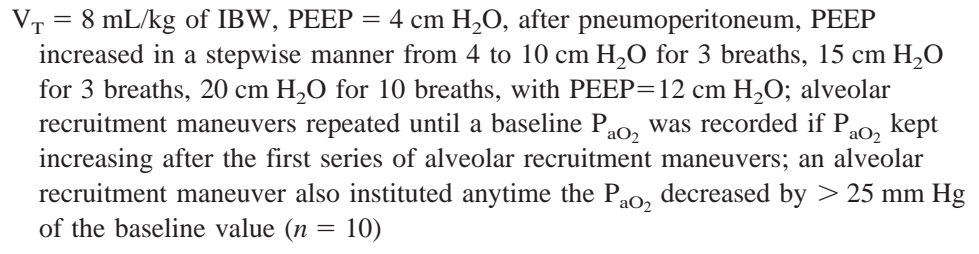 \\
\hline \multicolumn{3}{|c|}{$\begin{array}{l}\mathrm{V}_{\mathrm{T}}=\text { tidal volume } \\
\mathrm{IBW}=\text { ideal body weight } \\
\mathrm{PIP}=\text { peak inspiratory pressure } \\
\mathrm{I}: \mathrm{E}=\text { inspiratory-expiratory ratio }\end{array}$} \\
\hline
\end{tabular}

complications in the control group on postoperative day 1 compared with the alveolar recruitment maneuver group, but they found no significant difference thereafter.

Postoperative $\mathbf{P}_{\mathrm{aO}_{2}}$ or $\mathrm{S}_{\mathrm{pO}_{2}}$. Four studies found no significant difference in postoperative $\mathrm{P}_{\mathrm{aO}_{2}}$ or $\mathrm{S}_{\mathrm{pO}_{2}}$ between groups. Almarakbi et $\mathrm{al}^{27}$ found that the highest $\mathrm{S}_{\mathrm{pO}_{2}}$ occurred in the alveolar recruitment maneuver group with PEEP. Severgnini et $\mathrm{al}^{28}$ reported a statistically significant decrease in $\mathrm{S}_{\mathrm{pO}_{2}}$ in the control group on postoperative days 1 and 3 , whereas the $\mathrm{S}_{\mathrm{pO}_{2}}$ remained the same in the alveolar recruitment maneuver group.

Complications of Alveolar Recruitment Maneuvers. Four of the studies reported no complications with the use of alveolar recruitment maneuvers. Complications of al- veolar recruitment maneuvers were variably defined as hypotension (mean arterial blood pressure of $<60 \mathrm{~mm} \mathrm{Hg}$ ), hypertension (systolic blood pressure of $>150 \mathrm{~mm} \mathrm{Hg}$ ), an $\mathrm{S}_{\mathrm{pO}_{2}}$ of $<90 \%$, pneumothorax requiring a chest tube, a heart rate of $<60$ beats $/ \mathrm{min}$, and a need to give a fluid bolus or vasoactive medication. Severgnini et al ${ }^{28}$ noted comparable complications between the alveolar recruitment maneuver and control groups. Whalen et al ${ }^{19}$ identified an increase in the amount of vasopressors used in the alveolar recruitment maneuver group compared with the control group, but this difference was not statistically significant.

Frequency of Alveolar Recruitment Maneuvers. As stated earlier, the frequency of alveolar recruitment maneuvers varied among the studies in this review. Pang 


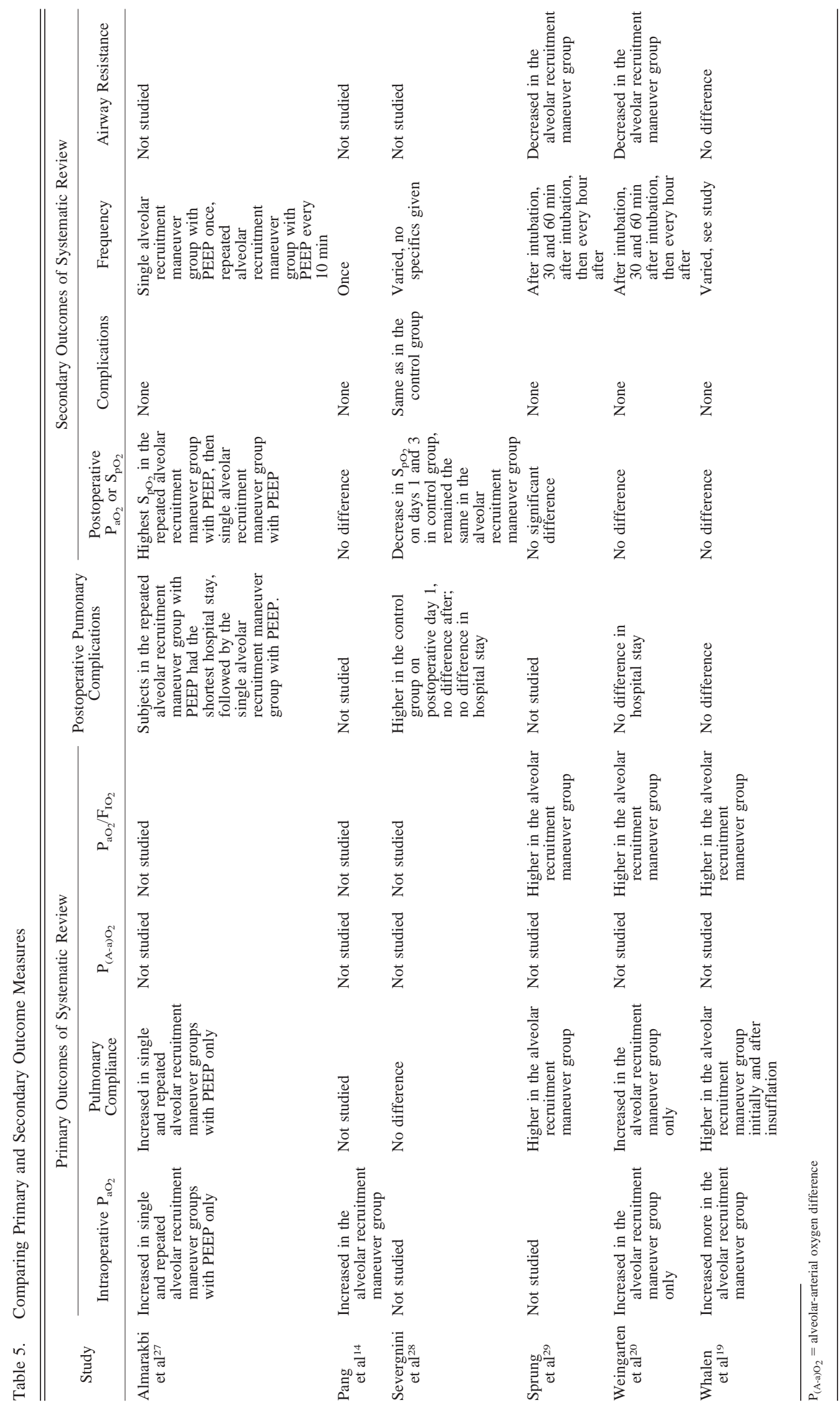


et $\mathrm{al}^{14}$ utilized an alveolar recruitment maneuver only once, whereas Sprung et $\mathrm{al}^{29}$ and Weingarten et $\mathrm{al}^{20}$ performed alveolar recruitment maneuvers after intubation, 30 and $60 \mathrm{~min}$ following intubation, and every hour thereafter. The study by Almarakbi et $\mathrm{al}^{27}$ was unique in that it was the only study to include the effects of different frequencies of alveolar recruitment maneuvers. These researchers compared alveolar recruitment maneuvers performed once with those performed every $10 \mathrm{~min}$.

\section{Discussion}

\section{Summary of Main Results}

This review of alveolar recruitment maneuvers included 6 RCTs, all of which achieved a score of $\geq 3$ on the Jadad scale. The studies differed in their subjects, independent/dependent variables, control and intervention groups, technique of applying an alveolar recruitment maneuver, and outcome measures, making absolute quantitative comparisons treacherous. We included the major clinical themes section below to qualitatively approach comparisons in this systematic review. Despite differences in methods, certain comparisons can be made among the 6 studies. Subjects in all studies underwent abdominal surgery. Most subjects had a body mass index of $>25 \mathrm{~kg} / \mathrm{m}^{2}$ and no significant pre-existing lung disease. Most studies utilized one of 2 methods for the application of alveolar recruitment maneuvers, with the exception of Severgnini et al. ${ }^{28}$ Alveolar recruitment maneuvers consisted of either a stepwise increase in PEEP with sustained breaths or sustained manual inflations of an anesthesia reservoir bag to a PIP of $40 \mathrm{~cm} \mathrm{H}_{2} \mathrm{O}$. All studies reported $P<.05$ as a statistically significant outcome difference.

\section{Primary Outcome Measures}

Overall, subjects in the alveolar recruitment maneuver groups experienced a higher intraoperative $\mathrm{P}_{\mathrm{aO}}$, greater lung compliance, and higher $\mathrm{P}_{\mathrm{aO}_{2}} / \mathrm{F}_{\mathrm{IO}_{2}}$.

\section{Secondary Outcome Measures}

Overall, there were no significant differences in the rate of postoperative pulmonary complications, postoperative $\mathrm{P}_{\mathrm{aO}_{2}}, \mathrm{~S}_{\mathrm{pO}_{2}}$, or intraoperative airway resistance between subjects in the alveolar recruitment maneuver and control groups in the 6 studies in this review. Despite the variety of maximum PIP allowed during alveolar recruitment maneuvers in the studies (ranging from 40 to $50 \mathrm{~cm} \mathrm{H}_{2} \mathrm{O}$ ), the occurrence of complications associated with alveolar recruitment maneuvers appeared minimal to nonexistent. Five of the 6 studies reported no complications associated with the use of alveolar recruitment maneuvers. The study that reported complications in the alveolar recruitment maneuver group had similar complications in the control group. ${ }^{28}$ The frequency of alveolar recruitment maneuvers varied among studies in this review. 14,19,20,27-29

\section{Major Clinical Themes}

Is There Evidence to Support Alveolar Recruitment Maneuvers in Open Abdominal Surgery? Of the 3 studies involving open abdominal surgery, only Weingarten et $\mathrm{al}^{20}$ included the effects of alveolar recruitment maneuvers on intraoperative $\mathrm{P}_{\mathrm{a}}{ }_{2}$, which increased solely in the alveolar recruitment maneuver group. Sprung et $\mathrm{al}^{29}$ and Weingarten et a ${ }^{20}$ reported an increase in pulmonary compliance along with an increase in $\mathrm{P}_{\mathrm{aO}_{2}} / \mathrm{F}_{\mathrm{IO}_{2}}$ in the alveolar recruitment maneuver groups. Severgnini et al ${ }^{28}$ found no significant difference in pulmonary compliance among groups and did not report on $\mathrm{P}_{\mathrm{aO}} / \mathrm{F}_{\mathrm{IO}_{2}}$. None of the studies reported statistically significant complications during or after alveolar recruitment maneuvers. There was no consensus on the benefit of alveolar recruitment maneuvers in the postoperative period.

Is There Evidence to Support Alveolar Recruitment Maneuvers in Laparoscopic Abdominal Surgery? All 3 studies involving laparoscopic abdominal surgery showed an increase in intraoperative $\mathrm{P}_{\mathrm{aO}}$ with alveolar recruitment maneuvers. ${ }^{14,19,27}$ Both Almarakbi et al ${ }^{27}$ and Whalen et al ${ }^{19}$ also reported an increase in pulmonary compliance, whereas Pang et a ${ }^{14}$ did not include pulmonary compliance in their research. Only Whalen et al ${ }^{19}$ reported on intraoperative $\mathrm{P}_{\mathrm{aO}_{2}} / \mathrm{F}_{\mathrm{IO}_{2}}$, which was increased in the alveolar recruitment maneuver group. There was no consensus of evidence regarding postoperative benefits of alveolar recruitment maneuvers. Almarakbi et al ${ }^{27}$ reported a higher $\mathrm{S}_{\mathrm{pO}_{2}}$ and shorter hospital stays with the alveolar recruitment maneuver groups, whereas Whalen et $\mathrm{al}^{19}$ found no differences in the postoperative period between groups. The lack of consensus for the benefits of alveolar recruitment maneuvers extending into the postoperative period will be discussed below in the implications for practice section.

Which Alveolar Recruitment Maneuver Is the Best? Excluding the study by Severgnini et $a 1,{ }^{28}$ the different types of alveolar recruitment maneuvers were found to be equally effective. Both Almarakbi et $\mathrm{al}^{27}$ and Pang et $\mathrm{al}^{14}$ utilized sustained manual inflations up to a PIP of $40 \mathrm{~cm} \mathrm{H}_{2} \mathrm{O}$ for their alveolar recruitment maneuvers. Almarakbi et al ${ }^{27}$ utilized single sustained manual inflations for $15 \mathrm{~s}$, whereas Pang et al ${ }^{14}$ utilized 10 sustained manual inflations over $1 \mathrm{~min}$. Both studies found an increase in intraoperative $\mathrm{P}_{\mathrm{aO}_{2}}$ in the alveolar recruitment maneuver groups. However, only Almarakbi et al ${ }^{27}$ reported on pulmonary compliance, which showed an increase exclusively 
in the alveolar recruitment maneuver groups. Neither study reported on $\mathrm{P}_{\mathrm{aO}_{2}} / \mathrm{F}_{\mathrm{IO}_{2}}$ or airway resistance.

Three studies utilized stepwise increases in PEEP starting at $4 \mathrm{~cm} \mathrm{H}_{2} \mathrm{O}$ and ending at $20 \mathrm{~cm} \mathrm{H}_{2} \mathrm{O}$ as alveolar recruitment maneuvers. ${ }^{19,20,29}$ Of the 2 studies that included intraoperative $\mathrm{P}_{\mathrm{aO}},{ }^{19,20}$ there was a statistically significant increase in the alveolar recruitment maneuver groups. All 3 studies showed an improvement in pulmonary compliance in the alveolar recruitment maneuver groups. Only Sprung et al ${ }^{29}$ and Whalen et al ${ }^{19}$ included $\mathrm{P}_{\mathrm{aO}} / \mathrm{F}_{\mathrm{IO}_{2}}$ as an outcome measure, which was significantly increased in the alveolar recruitment maneuver groups in the intraoperative period.

Manual sustained hyperinflations require a shorter amount of time to perform, whereas stepwise increases in PEEP or $\mathrm{V}_{\mathrm{T}}$ may prevent untoward subject responses such as straining or coughing when the depth of anesthesia is equivocal.

How Long Should Alveolar Recruitment Maneuvers Be Held to Be Effective? The time that the manual alveolar recruitment maneuver is held to a set PIP varies in the literature. As stated previously, some authors consider inflation of the lungs for 5-30 s to a prescribed PIP as representative of alveolar recruitment maneuvers. ${ }^{15-18} \mathrm{Al}-$ marakbi et $\mathrm{a}^{27}$ held alveolar recruitment maneuvers for $15 \mathrm{~s}$. Pang et al ${ }^{14}$ did not specify a period of time for holding the alveolar recruitment maneuver. They utilized 10 alveolar recruitment maneuvers over $1 \mathrm{~min}$, which leaves, at best, a few seconds for an inspiratory hold if it indeed was utilized. The 3 studies involving stepwise increases in PEEP all performed them in the same manner. ${ }^{19,20,29}$ Subjects received 3 breaths when the PEEP was increased from 4 to $10 \mathrm{~cm} \mathrm{H}_{2} \mathrm{O}$, then received 3 breaths when the PEEP was increased from 10 to $15 \mathrm{~cm} \mathrm{H}_{2} \mathrm{O}$, and finally 10 breaths when the PEEP was increased to $20 \mathrm{~cm} \mathrm{H}_{2} \mathrm{O}$. Severgnini et $\mathrm{al}^{28}$ defined an alveolar recruitment maneuver as setting PIP to $45 \mathrm{~cm} \mathrm{H}_{2} \mathrm{O}$ with an inspiratory/expiratory ratio of $3: 1$. The $\mathrm{V}_{\mathrm{T}}$ was then increased in steps of $4 \mathrm{~mL} / \mathrm{kg}$ of ideal body weight until a plateau pressure of $30 \mathrm{~cm} \mathrm{H}_{2} \mathrm{O}$ was reached, at which time 3 breaths were given.

Is There Evidence to Support the Use of Repeated Alveolar Recruitment Maneuvers? The repeated-measures alveolar recruitment maneuver group in the study by Almarakbi et $\mathrm{al}^{27}$ showed the greatest improvement in intraoperative $\mathrm{P}_{\mathrm{aO}}$, pulmonary compliance, and postoperative $\mathrm{P}_{\mathrm{aO}}$. Most of the studies repeated alveolar recruitment maneuvers at various times throughout the surgery. The study by Almarakbi et $\mathrm{al}^{27}$ was the only study to measure the effects of different frequencies of alveolar recruitment maneuvers. One of the experimental groups received an alveolar recruitment maneuver once, whereas another received alveolar recruitment maneuvers every 10 min until completion of surgery. The researchers noted that the benefit of an elevated $\mathrm{P}_{\mathrm{aO}_{2}}$ in the single alveolar recruitment maneuver group was temporary, whereas the benefit was sustained in the repeated-measures alveolar recruitment maneuver group. The subjects in the repeatedmeasures alveolar recruitment maneuver group also had the shortest hospital stay.

Is There Evidence to Support Using Alveolar Recruitment Maneuvers Followed By PEEP? The only study to isolate the differences in the utilization of PEEP following an alveolar recruitment maneuver was undertaken by Almarakbi et al. ${ }^{27}$ As stated above, these researchers compared the effects of repeated alveolar recruitment maneuvers versus a single alveolar recruitment maneuver. They also included a third experimental group that received a single alveolar recruitment maneuver followed by zero PEEP. There were no significant differences between the single alveolar recruitment maneuver group without PEEP and the control group (PEEP of $10 \mathrm{~cm} \mathrm{H}_{2} \mathrm{O}$ only). Neither group showed an improvement in respiratory compliance, intraoperative or postoperative $\mathrm{P}_{\mathrm{aO}}$, or a reduction in hospital stay. There was, however, a significant advantage in compliance, intraoperative and postoperative $\mathrm{P}_{\mathrm{aO}}$, and reduction in hospital stay in the alveolar recruitment maneuver groups followed by PEEP.

What Is the Best Method for Determining the Effectiveness of Alveolar Recruitment Maneuvers? Besides obtaining an arterial blood gas and calculating the $\mathrm{P}_{(\mathrm{A}-\mathrm{a}) \mathrm{O}_{2}}$, there is a more practical and less invasive approach. Four of the 5 studies found a statistically significant increase in pulmonary compliance in alveolar recruitment maneuver groups. ${ }^{19,20,27,29}$ Dynamic pulmonary compliance is calculated by dividing $\mathrm{V}_{\mathrm{T}}$ by the difference between PIP and PEEP: dynamic compliance $=\mathrm{V}_{\mathrm{T}}$ (PIP - PEEP). Static pulmonary compliance is calculated by dividing $\mathrm{V}_{\mathrm{T}}$ by the difference between the plateau pressure $\left(\mathrm{P}_{\text {plat }}\right)$ and PEEP: static compliance $=\mathrm{V}_{\mathrm{T}} /\left(\mathrm{P}_{\text {plat }}-\mathrm{PEEP}\right)$. An increase in pulmonary compliance immediately following the application of an alveolar recruitment maneuver would presumably reflect a reduction in atelectasis and result in an increase in $\mathrm{P}_{\mathrm{aO}_{2}}$ due to better matching of ventilation and perfusion. To avoid the need to perform the above calculations, a more clinically relevant method for determining whether an increase in compliance has occurred can be utilized. During volume control continuous mandatory ventilation, the provider would note that the same $\mathrm{V}_{\mathrm{T}}$ is delivered at $\mathrm{a}$ lower PIP following application of alveolar recruitment maneuvers. With pressure control continuous mandatory ventilation, the provider would note that an increased $V_{T}$ is delivered at the same inspiratory pressure setting. Contemporary anesthesia ventilators often include options to 
display the pressure-volume loop and calculated dynamic compliance values, making it even easier to measure the effectiveness of alveolar recruitment maneuvers.

\section{Overall Completeness and Applicability of Evidence}

Evidence from the 6 included studies regarding the benefit of alveolar recruitment maneuvers in the postoperative period was lacking. ${ }^{14,19,20,27-29}$ Although postoperative measurements were evaluated, no study included a postoperative pulmonary protocol accounting for confounding variables. In addition, only one study included dosages used for reversal of neuromuscular blockade. ${ }^{14}$ Other primary and secondary outcomes were compared as noted. The applicability of the evidence summarized in this review is limited to adult subjects without extensive pre-existing pulmonary disease who are undergoing abdominal surgery.

\section{Quality of Evidence}

This systematic review was limited to RCTs, systematic reviews, and quantitative meta-analyses. Only high-quality RCTs that matched the inclusion criteria were selected. Of concern, the sample sizes of the included studies were small, which brings into question the ability of the studies to control and account for confounding variables. This statistical fragility may have elevated the risk of type I or type II errors. The lack of specific emergence or postoperative pulmonary protocols limits the applicability of postoperative measurements.

\section{Potential Bias in the Review Process}

The reviewers did not examine the results of individual studies until after all studies met the inclusion criteria, including achieving a score of $\geq 3$ on the Jadad scale. Reviewers were therefore unaware of the content of the included studies as it related to the benefit of alveolar recruitment maneuvers until after the studies were selected.

\section{Conclusions}

\section{Implications for Practice}

Depending on the type of surgery and patient status, the practitioner should utilize alveolar recruitment maneuvers followed by PEEP after induction of general endotracheal anesthesia, routinely, and in the presence of a decreasing $\mathrm{S}_{\mathrm{pO}_{2}}$. Although evidence from this review limits the application of alveolar recruitment maneuvers to adults undergoing abdominal surgery, there is a wealth of literature to support alveolar recruitment maneuvers in other surgeries..$^{31-34}$ Teleologically, a healthy human sighs an average of 9-10 times $/ \mathrm{h}$. Thus, most patients undergoing general endotracheal anes- thesia would benefit from this homeostatic reflex in the form of an alveolar recruitment maneuver.

Compared with the control group, all types of alveolar recruitment maneuvers were beneficial in the intraoperative period. Manual sustained hyperinflations require a short amount of time to perform, whereas stepwise increases in PEEP or $\mathrm{V}_{\mathrm{T}}$ may prevent untoward subject responses such as coughing or straining when the depth of anesthesia is questionable. Alveolar recruitment maneuvers should be performed instead of solely increasing $\mathrm{F}_{\mathrm{IO}_{2}}$ during the maintenance phase of anesthesia. Continually increasing $\mathrm{F}_{\mathrm{IO}_{2}}$ in the face of a decreasing $\mathrm{S}_{\mathrm{pO}_{2}}$ may maintain an elevated $\mathrm{S}_{\mathrm{pO}_{2}}$, but may also mask a physiological shunt. Oxygen can also adversely affect respiratory control, ventilation/perfusion ratios, and hypoxic pulmonary vasoconstriction, as well as cause vasoconstriction of systemic arterioles..$^{35}$ Oxygen products from reduced nicotinamide adenine dinucleotide phosphate oxidase also increase inflammation and tissue injury through a complex interaction among neutrophils, macrophages, and platelets. ${ }^{36}$ Alveolar recruitment maneuvers allow the anesthesia provider to reduce the $\mathrm{F}_{\mathrm{IO}_{2}}$ yet maintain a higher $\mathrm{S}_{\mathrm{pO}_{2}}$.

Current evidence does not support the assumption that the benefit of alveolar recruitment maneuvers extends to the postoperative period because none of the studies included a specific emergence or postoperative pulmonary protocol. Emergence from anesthesia and the immediate postoperative period can leave a patient susceptible to atelectasis and hypoxemia. Patients often breathe low $\mathrm{V}_{\mathrm{T}}$ without PEEP and on 100\% oxygen for minutes during this time. Given the negative consequences of absorption atelectasis, low $\mathrm{V}_{\mathrm{T}}$, and the absence of PEEP, techniques for emergence need to be re-examined to prevent the negation of intraoperative alveolar recruitment maneuvers. Teleologically, it seems implicit that reducing intraoperative risk may decrease postoperative issues.

\section{Implications for Research}

Most studies involve the use of alveolar recruitment maneuvers during the maintenance phase of anesthesia. To maximize the benefits of alveolar recruitment maneuvers for patients in the postoperative period, a study incorporating sigh breaths following extubation with the utilization of CPAP should be undertaken. Sigh breaths in the postoperative period can be quantified with the use of an incentive spirometer. After extubation, patients control their own gas composition and may benefit from CPAP in the post-anesthesia care unit to prevent atelectasis secondary to diminished $\mathrm{V}_{\mathrm{T}}$. The use of CPAP in the postoperative period significantly decreases the incidence of pneumonia, sepsis, and hypoxemia. ${ }^{37} \mathrm{~A}$ study on the use of intraoperative alveolar recruitment maneuvers combined with the use of CPAP and sigh breaths following extubation may 


\section{Alveolar Recruitment Maneuvers Under General Anesthesia}

extend the benefits of alveolar recruitment maneuvers into the recovery period, reducing postoperative pulmonary complications and improving subject outcomes.

Patient position during emergence and following extubation may also improve patient outcomes and reduce atelectasis formation. A study comparing elevated head-ofbed and supine positions during emergence and in the postoperative period may show a reduction in atelectasis and improvement in oxygenation.

\section{REFERENCES}

1. Bendixen HH, Smith GM, Mead J. Pattern of ventilation in young adults. J Appl Physiol 1964;19:195-198.

2. Bartlett D Jr. Origin and regulation of spontaneous deep breaths. Respir Physiol 1971;12(2):230-238.

3. Ferris BG Jr, Pollard DS. The effect of deep and quiet breathing on pulmonary compliance in man. J Clin Invest 1960;39:143-149.

4. Bendixen HH, Bullwinkel B, Hedley-Whyte J, Laver MB. Atelectasis and shunting during spontaneous ventilation in anesthetized subjects. Anesthesiology 1964;25:297-301.

5. Hedenstierna G, Edmark L. Mechanisms of atelectasis in the perioperative period. Best Pract Res Clin Anaesthesiol 2010;24(2):157-169.

6. Dietl P, Frick M, Mair N, Bertocchi C, Haller T. Pulmonary consequences of a deep breath revisited. Biol Neonate 2004;85(4):299304.

7. Froese AB, Bryan AC. Effects of anesthesia and paralysis on diaphragmatic mechanics in man. Anesthesiology 1974;41(3):245-255.

8. Tokics L, Hedenstierna G, Strandberg A, Brismar B, Lundquist H. Lung collapse and gas exchange during general anesthesia: effects of spontaneous breathing, muscle paralysis, and positive end-expiratory pressure. Anesthesiology 1987;66(2):157-167.

9. Magnusson L, Spahn DR. New concepts of atelectasis during general anaesthesia. Br J Anaesth 2003;91(1):61-72.

10. Brismar B, Hedenstierna G, Lundquist H, Strandberg A, Svensson L, Tokics L. Pulmonary densities during anesthesia with muscular relaxation-a proposal of atelectasis. Anesthesiology 1985;62(4):422-428.

11. Joyce $\mathrm{CJ}$, Baker AB. What is the role of absorption atelectasis in the genesis of perioperative pulmonary collapse. Anaesth Intensive Care 1995;23(6):691-696.

12. Hedenstierna G. Rothen HU. Atelectasis formation during anesthesia: causes and measures to prevent it. J Clin Monit Comput 2000; 16(5-6):329-335

13. Gonçalves LO, Cicarelli DD. Alveolar recruitment maneuver in anesthetic practice: how, when, and why it may be useful. Rev Bras Anestesiol 2005;55(6):631-638.

14. Pang CK, Yap J, Chen PP. The effect of an alveolar recruitment strategy on oxygenation during laparoscopic cholecystectomy. Anaesth Intensive Care 2003;31(2):176-180.

15. Biddle C, Epps L, Hassanein R. The efficacy of sighs in subjects with COPD undergoing general anesthesia and controlled ventilation. AANA J 1989;57(2):131-136.

16. Cakmakkaya OS, Kaya G, Altintas F, Hayirlioglu M, Ekici B. Restoration of pulmonary compliance after laparoscopic surgery using a simple alveolar recruitment maneuver. J Clin Anesth 2009;21(6):422-426.

17. Celebi S, Köner O, Menda F, Korkut K, Suzer K, Cakar N. The pulmonary and hemodynamic effects of two different recruitment maneuvers after cardiac surgery. Anesth Analg 2007;104(2):384-390.

18. Rothen HU, Neumann P, Berglund JE, Valtysson J, Magnusson A, Hedenstierna G. Dynamics of re-expansion of atelectasis during general anaesthesia. Br J Anaesth 1999;82(4):551-556.

19. Whalen FX, Gajic O, Thompson GB, Kendrick ML, Que FL, Williams BA, et al. The effects of the alveolar recruitment maneuver and positive end-expiratory pressure on arterial oxygenation during laparoscopic bariatric surgery. Anesth Analg 2006;102(1):298-305.

20. Weingarten TN, Whalen FX, Warner DO, Gajic O, Schears GJ, Snyder MR, et al. Comparison of two ventilatory strategies in elderly subjects undergoing major abdominal surgery. Br J Anaesth 2010; 104(1):16-22.

21. Shander A, Fleisher LA, Barie PS, Bigatello LM, Sladen RN, Watson $\mathrm{CB}$. Clinical and economic burden of postoperative pulmonary complications: subject safety summit on definition, risk-reducing interventions, and preventive strategies. Crit Care Med 2011;39(9): 2163-2172

22. Tusman G, Böhm SH, Warner DO, Sprung J. Atelectasis and perioperative pulmonary complications in high-risk subjects. Curr Opin Anaesthesiol 2012;25(1):1-10.

23. Magnusson L, Zemgulis V, Wicky S, Tydén H, Thelin S, Hedenstierna G. Atelectasis is a major cause of hypoxemia and shunt after cardiopulmonary bypass: an experimental study. Anesthesiology. 1997;87(5):1153-1163.

24. Linde-Zwirble WL, Bloom JD, Mecca RS, Hansell DM. Postoperative pulmonary complications in adult elective surgery subjects in the US: severity, outcomes, and resources use. Critical Care 2010; 14(Suppl 1):P210.

25. Paulus F, Binnekade JM, Vroom MB, Schultz MJ. Benefits and risks of manual hyperinflation in intubated and mechanically ventilated intensive care unit subjects: a systematic review. Crit Care 2012; 16(4):R145

26. Jadad AR, Moore RA, Carroll D, Jenkinson C, Reynolds DJ, Gavaghan DJ, McQuay HJ. Assessing the quality of reports of randomized clinical trials: Is blinding necessary? Controlled Clin Trials 1996;17(1):1-12

27. Almarakbi WA, Fawzi HM, Alhashemi JA. Effects of four intraoperative ventilatory strategies on respiratory compliance and gas exchange during laparoscopic gastric banding in obese subjects. Br J Anaesth 2009;102(6):862-868.

28. Severgnini P, Selmo G, Lanza C, Chiesa A, Frigerio A, Bacuzzi A, et al. Protective mechanical ventilation during general anesthesia for open abdominal surgery improves postoperative pulmonary function. Anesthesiology 2013;118(6):1307-1321.

29. Sprung J, Whalen FX, Comfere T, Bosnjak ZJ, Bajzer Z, Gajic O, et al. Alveolar recruitment and arterial desflurane concentration during bariatric surgery. Anesth Anal 2009;108(1):120-127.

30. Futier E, Constantin JM, Paugam-Burtz C, Pascal J, Eurin M, Neuschwander A, et al. A trial of intraoperative low-tidal-volume ventilation in abdominal surgery. N Engl J Med 2013;369(5):428-437.

31. Duff JP, Rosychuk RJ, Joffe AR. The safety and efficacy of sustained inflations as a lung recruitment maneuver in pediatric intensive care unit patients. Intensive Care Medicine 2007;33(10):1778-1786.

32. Fan E, Wilcox ME, Brower RG, Stewart TE, Mehta S, Lapinsky SE, et al. Recruitment maneuvers for acute lung injury: a systematic review. Am J Respir Crit Care Med 2008;178(11):1156-1163.

33. Claxton BA, Morgan P, McKeague H, Mulpur A, Berridge J. Alveolar recruitment strategy improves arterial oxygenation after cardiopulmonary bypass. Anaesthesia 2003;58(2):111-116.

34. Unzueta C, Tusman G, Suarez-Sipmann F, Böhm S, Moral V. Alveolar recruitment improves ventilation during thoracic surgery: a randomized controlled trial. Br J Anaesth 2012;108(3):517-524.

35. Lumb AB, Walton LJ. Perioperative oxygen toxicity. Anesthesiol Clin 2012;30(4):591-605.

36. Ward PA, Warren JS, Johnson KJ. Oxygen radicals, inflammation, and tissue injury. Free Radic Biol Med 1988;5(5-6):403-408.

37. Squadrone V, Coha M, Cerutti E, Schellino MM, Biolino P, Occella $\mathrm{P}$, et al. Continuous positive airway pressure for treatment of postoperative hypoxemia: a randomized controlled trial. JAMA 2005; 293(5):589-595. 